\title{
Study of Impacts of \\ Global Warming on Climate Change: \\ Rise in Sea Level and Disaster Frequency
}

\author{
Bharat Raj Singh and Onkar Singh \\ Additional information is available at the end of the chapter
}

http://dx.doi.org/10.5772/50464

\section{Introduction}

Global warming and climate change refer to an increase in average global temperatures. Natural events and human activities are believed to be main contributors to such increases in average global temperatures. The climate change, caused by rising emissions of carbon dioxide from vehicles, factories and power stations, will not only effects the atmosphere and the sea but also will alter the geology of the Earth. Emissions of carbon dioxide due to our use of fossil energy will change the climate and the temperature is estimated to increase by 2 to $6^{\circ}$ Celsius within year 2100, which is a tremendous increase from our current average temperature of $1.7^{\circ}$ Celsius as predicted by IPCC. This may cause huge changes to our civilization, both positive and negative, but the total impact on our society is currently very uncertain. Forecasts indicate that major storms could devastate New York City in next decade whereas Gulf countries will get affected badly well before.

Global warming primarily caused by increases in "greenhouse" gases such as Carbon Dioxide $\left(\mathrm{CO}_{2}\right)$, Nitrous oxide (NOx), Sulphur dioxide $\left(\mathrm{SO}_{2}\right)$, Hydrogen etc., . A warming planet thus leads to climate changes which can adversely affect weather in different ways. Some of the prominent indicators for a global warming are detailed below:

i. Temperature over land

ii. Snow cover on Hills

iii. Glaciers on Hills

iv. Ocean Heat content

v. Sea Ice

vi. Sea level

vii. Sea surface temperature 
viii. Temperature Over Ocean

ix. Humidity

x. Tropospheric Temperature

Past decade, according to Scientists in 48 Countries, it was recorded warmest time phase during meeting of National Oceanic and Atmospheric Administration (NOAA), on July 28, 2010. Although since decades, scientists and environmentalists have been warning that the way we are using Earth's resources is not sustainable. Alternative technologies have been called for repeatedly, seemingly falling upon deaf ears or, cynically, upon those who don't want to make substantial changes as it challenge their bottom line and reduces their current profits.

Global warming in today's scenario is threat to the survival of mankind. In 1956, an US based Chief consultant and oil geologist Marion King Hubert, (1956) predicted that if oil is consumed with high rate, US oil production may peak in 1970 and thereafter it will decline. He also described that other countries may attain peak oil day within 20-30 years and many more may suffer with oil crises within 40 years, when oil wells are going to dry. He illustrated the projection with a bell shaped Hubert Curve based on the availability and its consumptions of the fossil fuel. Large fields are discovered first, small ones later. After exploration and initial growth in output, production plateaus and eventually declines to zero.

Crude oil, coal and gas are the main resources for world energy supply. The size of fossil fuel reserves and the dilemma that when non-renewable energy will be diminished, is a fundamental and doubtful question that needs to be answered. A new formula for calculating, when fossil fuel reserves are likely to be depleted, is presented along with an econometrics model to demonstrate the relationship between fossil fuel reserves and some main variables (Shahriar Shafiee et.al. 2009). The new formula is modified from the Klass model and thus assumes a continuous compound rate and computes fossil fuel reserve depletion times for oil, coal and gas of approximately 35, 107 and 37 years, respectively. This means that coal reserves are available up to 2112 , and will be the only fossil fuel remaining after 2042.

In India, vehicular pollution is estimated to have increased eight times over the last two decades. This source alone is estimated to contribute about 70 per cent to the total air pollution. With 243.3 million tons of carbon released from the consumption and combustion of fossil fuels in 1999, India is ranked fifth in the world behind the U.S., China, Russia and Japan. India's contribution to world carbon emissions is expected to increase in the coming years due to the rapid pace of urbanization, shift from non-commercial to commercial fuels, increased vehicular usage and continued use of older and more inefficient coal-fired and fuel power-plants (Singh, BR, et al., 2010).

Thus, peak oil year may be the turning point for mankind which may lead to the end of 100 year of easy growth, if self-sufficiently and sustainability of energy is not maintained on priority. This chapter describes the efforts being made to explore non-conventional energy resources such as: solar energy, wind energy, bio-mass and bio-gas, hydrogen, bio-diesel which may help for the sustainable fossil fuel reserves and reduce the tail pipe emission and 
other pollutants like: $\mathrm{CO}_{2}$, $\mathrm{NOx}$ etc.. The special emphasis is also given for the storage of energy such as compressed air stored from solar, wind and or other resources like: climatic energy to maintain energy sustainability of $21^{\text {st }}$ century. This may also leads to environmentally and ecologically better future.

\section{Weather watch: Byron's view of the glaciers}

In September 1816, Lord Byron set off from Geneva with his friend Hob house, and kept a journal for his half-sister Augusta. Lodged at the Curate's, set out to see the Valley; heard an Avalanche fall, like thunder; saw Glacier - enormous. Storm came on, thunder, lightning, hail; all in perfection, and beautiful (Fig 1).

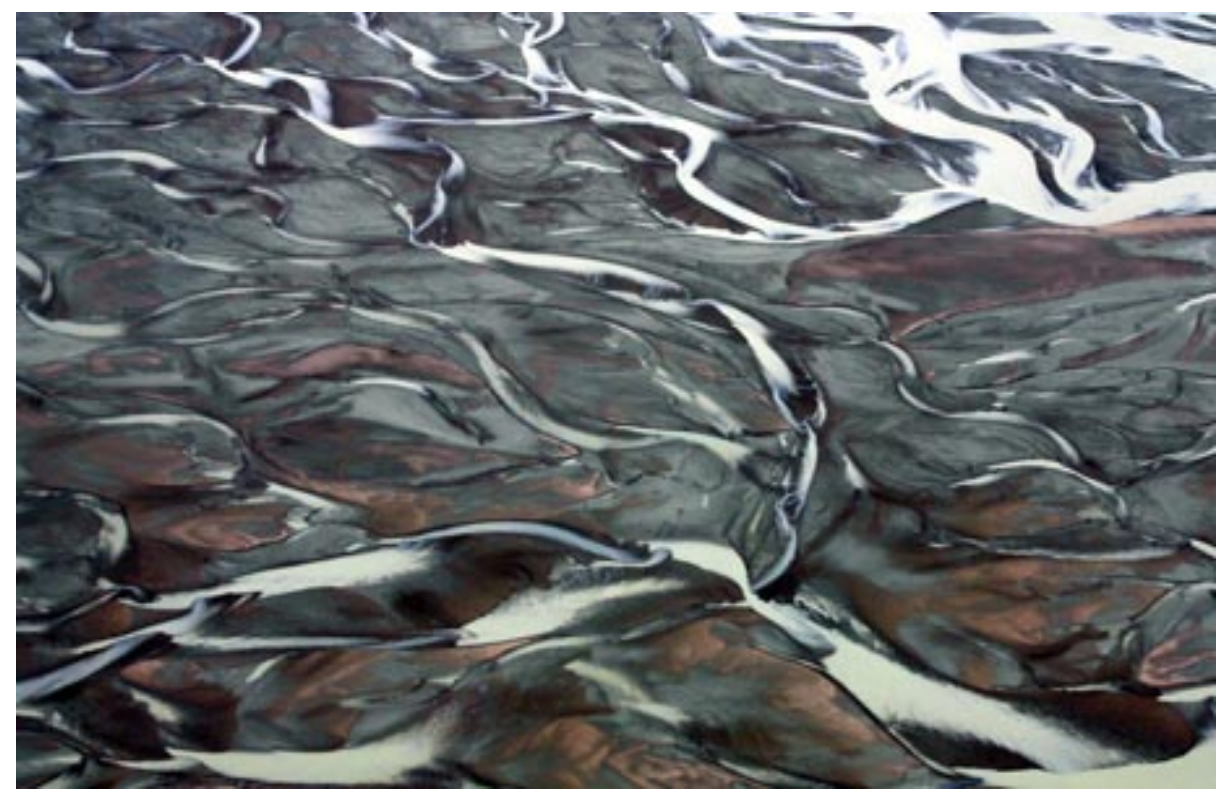

Figure 1. Byron described glaciers in Geneva as "neither mist nor water" in September 1816. (Photograph: John Mcconnico/AP)

He said that he was on horseback; Guide wanted to carry his cane; he was going to give it to him, when he recollected that it was a Swordstick, and he thought lightning might be attracted towards him; kept it himself; a good deal encumbered with it, and his cloak, as it was too heavy for a whip, and the horse was stupid, and stood still with every other peal," he records in Byron: Selections from Poetry, Letters \& Journals (Nonesuch Press.)

Got in, not very wet; the cloak being staunch, $\mathrm{H}$ wet though. $\mathrm{H}$ took refuge in a cottage; sent man, umbrella and cloak (from the Curate's when he arrived) after him. He sees a torrent like the tail of a white horse streaming in the wind, such as it might be conceived would be that of the 'pale horse' on which Death is mounted in the Apocalypse. It is neither mist nor water, but something between both; its immense height (nine hundred feet) gives it a wave, 
a curve, a spreading here, a condensation there, wonderful and indescribable. He looks again the next day: the Sun upon it forming a rainbow of the lower part of all colours, but principally purple and gold; the bow moving as you move; he never saw anything like this.

\section{Global warming issues}

\subsection{Effect of global warming}

With increases in the Earth's global mean temperature i.e., global warming, the various effects on climate change pose risks that increases. The IPCC (2001d and 2007d) has organized many of these risks into five "reasons for concern:

- Threats to endangered species and unique systems,

- Damages from extreme climate events,

- Effects that fall most heavily on developing countries and

- The poor within countries, global aggregate impacts (i.e., various measurements of total social, economic and ecological impacts), and large-scale high-impact events.

The effects, or impacts, of climate change may be physical, ecological, social or economic. Evidence of observed climate change includes the instrumental temperature record, rising sea levels, and decreased snow cover in the Northern Hemisphere. According to the Intergovernmental Panel on Climate Change (IPCC, 2007a:10), "[most] of the observed increase in global average temperatures since the mid-20th century is very likely due to the observed increase in [human greenhouse gas] concentrations". It is predicted that future climate changes will include further global warming (i.e., an upward trend in global mean temperature), sea level rise, and a probable increase in the frequency of some extreme weather events. United Nations Framework Convention on Climate Change has agreed to implement policies designed to reduce their emissions of greenhouse gases.

\subsection{Effect of climate change}

The phrase climate change is used to describe a change in the climate, measured in terms of its statistical properties, e.g., the global mean surface temperature. In this context, climate is taken to mean the average weather. Climate can change over period of time ranging from months to thousands or millions of years. The classical time period is 30 years, as defined by the World Meteorological Organization. The climate change referred to may be due to natural causes, e.g., changes in the sun's output, or due to human activities, e.g., changing the composition of the atmosphere. Any human-induced changes in climate will occur against the background of natural climatic variations.

Climate change reflects a change in the energy balance of the climate system, i.e. changes the relative balance between incoming solar radiation and outgoing infrared radiation from Earth. When this balance changes it is called "radiative forcing", and the calculation and measurement of radiative forcing is one aspect of the science of climatology. The processes that cause such changes are called "forcing mechanisms". Forcing mechanisms can be either "internal" or "external". Internal forcing mechanisms are natural processes within the climate 
system itself, e.g., the meridional turnover. External forcing mechanisms can be either natural (e.g., changes in solar output) or anthropogenic (e.g., increased emissions of greenhouse gases).

Whether the initial forcing mechanism is internal or external, the response of the climate system might be fast (e.g., a sudden cooling due to airborne volcanic ash reflecting sunlight), slow (e.g. thermal expansion of warming ocean water), or a combination (e.g., sudden loss of albedo in the arctic ocean as sea ice melts, followed by more gradual thermal expansion of the water). Therefore, the climate system can respond abruptly, but the full response to forcing mechanisms might not be fully developed for centuries or even longer.

The most general definition of climate change is a change in the statistical properties of the climate system when considered over long periods of time, regardless of cause, whereas Global warming" refers to the change in the Earth's global average surface temperature. Measurements show a global temperature increase of $1.4^{\circ} \mathrm{F}\left(0.78^{\circ} \mathrm{C}\right)$ between the years 1900 and 2005. Global warming is closely associated with a broad spectrum of other climate changes, such as:

- Increases in the frequency of intense rainfall,

- Decreases in snow cover and sea ice,

- More frequent and intense heat waves,

- $\quad$ Rising sea levels, and

- Widespread ocean acidification.

\subsubsection{Risk of intense rainfall}

There are two studied made here to elaborate the risk of intense rain fall one by United States and other one by United Kingdom. They have warned that these risks are due to extreme climate change, thus we have to curb the global warming issues in phases. The summaries of study are given below:

i. Two 500-Year Floods in Just 15 Years: In the United States, The Great Flood of 1993devastating communities along the Mississippi River and its tributaries in nine Midwestern states - was one of the most costly disasters. Thousands of Americans were displaced from their homes and forced to leave their lives behind, hundreds of levees failed, and damages soared to an estimated \$12 to 16 billion. A mere 15 years later, history is repeating itself in the Midwest as the rainswollen Cedar, Illinois, Missouri and Mississippi Rivers and their tributaries top their banks and levees, leaving hundreds of thousands of people displaced. With rainfall in May-June 2008 about two to three times greater than the long-term average, soybean planting is behind schedule and some crops may have to be replanted. This remarkably quick return of such severe flooding is not anticipated by currently used out-of-date methodologies, but is what we should expect as global warming leads to more frequent and intense severe storms. Inadequate floodplain management is also responsible for the extent of damages from both floods, especially over-reliance on levees and the false sense of security they 
provide to those who live behind them. About 28 percent of the total new development in the seven states over the past 15 years has been in areas within the 1993 flood events. The National Wildlife Federation says that to limit the magnitude of changes to the climate and the impacts on communities and wildlife, we must curb global warming pollution. The National Wildlife Federation recommends that policy makers, industry, and individuals take steps to reduce global warming pollution from today's levels by 80 percent by 2050. That's a reduction of 20 percent per decade or just 2 percent per year. Science tells us that this is the only way to hold warming in the next century to no more than $2^{\circ} \mathrm{F}$. This target is achievable with technologies either available or under development, but we need to start taking action now to avoid the worst impacts (See: www.nwf.org/globalwarming).

ii. Extreme rainfall and flood risk in the UK: Multi-day rainfall events are an important cause of recent severe flooding in the UK and any change in the magnitude of such events may have severe impacts upon urban structures such as dams, urban drainage systems and flood defences and cause failures to occur. Regional pooling of 1-, 2-, 5- and 10-day annual maxima for 1961 to 2000 from 204 sites across the UK is used in a standard regional frequency analysis to produce GEV growth curves for long return-period rainfall events for each of nine defined climatological regions. Temporal changes in 1-, 2-, 5- and 10-day annual maxima are examined with L-moments using both a 10-year moving window and fixed decades from 1961-70, 1971-80, 1981-90 and 1991-2000. A bootstrap technique is then used to assess uncertainty in the fitted decadal growth curves and to identify significant trends in both distribution parameters and quantile estimates.

There has been a two-part change in extreme rainfall event occurrence across the UK from 1961-2000. Little change is observed at 1- and 2-day duration, but significant decadal level changes are seen in 5- and 10-day events in many regions. In the south of the UK, growth curves have flattened and 5- and 10-day annual maxima have decreased during the 1990s. However, in the north, the 10-day growth curve has steepened and annual maxima have risen during the 1990s. This is particularly evident in Scotland. The 50-year event in Scotland during 1961-1990 has become an 8-, 11- and 25-year event in the Eastern, Southern and Northern Scotland pooling regions respectively during the 1990s. In northern England the average recurrence interval has also halved. This may have severe implications for design and planning practices in flood control.

Increasing flood risk is now recognised as the most important sectoral threat from climate change in most parts of the world, with recent repeated severe flooding in the UK and Europe causing major loss of property and life, and causing the insurance industry to threaten the withdrawal of flood insurance cover from millions of UK households. This has prompted public debate on the apparent increased frequency of extremes and focussed attention in particular on perceived increases in rainfall intensities. Climate model integrations predict increases in both the frequency and intensity of heavy rainfall in the high latitudes under enhanced greenhouse conditions. These projections are consistent with recent increases in rainfall intensity seen in the UK and worldwide. 


\subsubsection{Decreases in snow cover and sea ice}

Decreasing snow cover and land-ice extent continue to be positively correlated with increasing landsurface temperatures: Satellite data show that it is quite likely to have been decreases of about $10 \%$ in the extent of snow cover since the late 1960s. There is a highly significant correlation between increases in Northern Hemisphere land temperatures and the decreases. There is now ample evidence to support a major retreat of alpine and continental glaciers in response to 20th century warming. In a few maritime regions, increases in precipitation due to regional atmospheric circulation changes have overshadowed increases in temperature in the past two decades, and glaciers have re-advanced. Over the past 100 to 150 years, ground-based observations show that there is possibility of a reduction of about two weeks in the annual duration of lake and river ice in the mid- to high latitudes of the Northern Hemisphere (Fig.2).

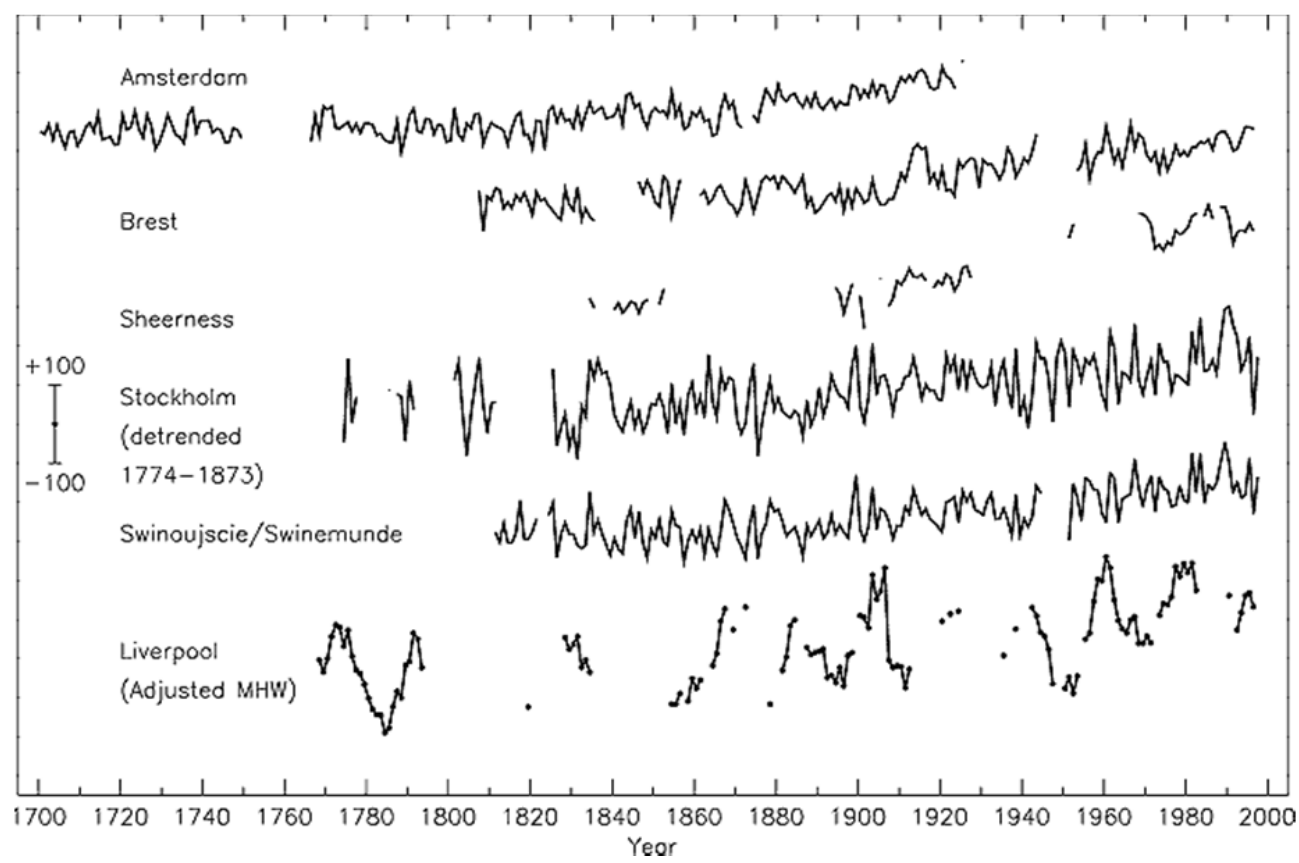

Figure 2. Time-series of relative sea level for the past 300 years from Northern Europe: Amsterdam, Netherlands; Brest, France; Sheerness, UK; Stockholm, Sweden (detrended over the period 1774 to 1873 to remove to first order the contribution of post-glacial rebound); Swinoujscie, Poland (formerly Swinemunde, Germany); and Liverpool, UK. Data for the latter are of "Adjusted Mean High Water" rather than Mean Sea Level and include a nodal (18.6 year) term. The scale bar indicates $\pm 100 \mathrm{~mm}$.

Northern Hemisphere sea-ice amounts are decreasing, but no significant trends in Antarctic sea-ice extent are apparent: A retreat of sea-ice extent in the Arctic spring and summer of 10 to $15 \%$ since the 1950s is consistent with an increase in spring temperatures and, to a lesser extent, summer temperatures in the high latitudes. There is little indication of reduced Arctic sea- 
ice extent during winter when temperatures have increased in the surrounding region. By contrast, there is no readily apparent relationship between decadal changes of Antarctic temperatures and sea-ice extent since 1973. After an initial decrease in the mid-1970s, Antarctic sea-ice extent has remained stable, or even slightly increased.

New data indicate that there likely has been an approximately 40\% decline in Arctic sea-ice thickness in late summer to early autumn between the period of 1958 to 1976 and the mid-1990s, and a substantially smaller decline in winter: The relatively short record length and incomplete sampling limit the interpretation of these data. Interannual variability and inter-decadal variability could be influencing these changes.

\subsubsection{More frequent and intense heat waves}

A recent study shows that an increase in heat-absorbing greenhouse gases intensifies an unusual atmospheric circulation pattern already observed during heat waves in Europe and North America. As the pattern becomes more pronounced, severe heat waves occur in the Mediterranean region and the southern and western United States. Other parts of France, Germany and the Balkans also become more susceptible to severe heat waves. "Extreme weather events will have some of the most severe impacts on human society as climate changes, "says Meehl.

Heat waves can kill more people in a shorter time than almost any other climate event. According to records, 739 people died as a result of Chicago's July, 1995, heat wave. Fifteen thousand Parisians are estimated to have died from heat in August, 2003, along with thousands of farm animals. For the study, Meehl and Tebaldi compared present (1961-1990) and future (2080-2099) decades to determine how greenhouse gases and sulfate aerosols might affect future climate in Europe and the United States, focusing on Paris and Chicago. They assumed little policy intervention to slow the buildup of greenhouse gases. During the Paris and Chicago heat waves, atmospheric pressure rose to values higher than usual over Lake Michigan and Paris, producing clear skies and prolonged heat. In the model, atmospheric pressure increases even more during heat waves in both regions as carbon dioxide accumulates in the atmosphere.

Heat wave is based on the concept of exceeding specific thresholds, thus allowing analyses of heat wave duration and frequency. Three criteria were used to define heat waves in this way, which relied on two location-specific thresholds for maximum temperatures. Threshold 1 (T1) was defined as the 97.5th percentile of the distribution of maximum temperatures in the observations and in the simulated present-day climate (seasonal climatology at the given location), and T2 was defined as the 81st percentile. A heat wave was then defined as the longest period of consecutive days satisfying the following three conditions:

i. The daily maximum temperature must be above $\mathrm{T} 1$ for at least 3 days,

ii. The average daily maximum temperature must be above $\mathrm{T} 1$ for the entire period, and

iii. The daily maximum temperature must be above T2 for every day of the entire period. 
Because the Chicago heat wave of 1995 and the Paris heat wave of 2003 had particularly severe impacts, we chose grid points from the model that were close to those two locations to illustrate heat wave characteristics. This choice was subjective and illustrative given that there are, of course, other well-known heat waves from other locations. Also, we are not suggesting that a model grid point is similar to a particular weather station; we picked these grid points because they represent heat wave conditions for regions representative of Illinois and France in the model, and therefore they can help identify processes that contribute to changes in heat waves in the future climate in those regions. We chose comparable grid points from the National Centers for Environmental Prediction (NCEP)/NCAR reanalyses that used assimilated observational data for comparison to the model results.

Heat waves in Chicago, Paris, and elsewhere in North America and Europe will become more intense, more frequent and longer lasting in the 21st century, according to a new modeling study by two scientists at the National Center for Atmospheric Research (NCAR) in Boulder, Colo. In the United States, heat waves will become most severe in the West and South. The findings appear in the August 13(2004) issue of the journal Science. Gerald Meehl and Claudia Tebaldi, both of NCAR, examined Earth's future climate using the Parallel Climate Model, developed by NCAR and the U.S. Department of Energy (DOE).

During the 1995 Chicago heat wave, the most severe health impacts resulted from the lack of cooling relief several nights in a row, according to health experts. In the model, the western and southern United States and the Mediterranean region of Europe experience a rise in nighttime minimum temperatures of more than 3 degrees Celsius (5.4 degrees Fahrenheit) three nights in a row. They will occur more often: The average number of heat waves in the Chicago area increases in the coming century by 25 percent, from "Heat Waves of the 21st Century: More Intense, More Frequent and Longer Lasting." (Source: PHYSorg.com. 12 Aug 2004, http://phys.org/news806.html Page 1/21.66 per year to 2.08).

In Paris, the average number increases 31percent, from 1.64 per year to 2.15. They will last longer: Chicago's present heat waves last from 5.39 to 8.85 days; future events increase to between 8.5 and 9.24 days. In Paris, present-day heat waves persist from 8.33 to 12.69 days; they stretch to between 11.39 and 17.04 days in future decades.(Source: National Science Foundation)

\subsubsection{Observed changes in sea level}

Based on tide gauge data, the rate of global mean sea level rise during the 20th century is in the range 1.0 to $2.0 \mathrm{~mm} / \mathrm{yr}$, with a central value of $1.5 \mathrm{~mm} / \mathrm{yr}$ (the central value should not be interpreted as a best estimate.

i. The causes for change of the sea level: At the shoreline it is determined by many factors in the global environment that operate on a great range of time-scales, from hours (tidal) to millions of years (ocean basin changes due to tectonics and sedimentation). On the time-scale of decades to centuries, some of the largest influences on the average levels of the sea are linked to climate and climate change processes. 
Firstly, as ocean water warms, it expands. On the basis of observations of ocean temperatures and model results, thermal expansion is believed to be one of the major contributors to historical sea level changes. Further, thermal expansion is expected to contribute the largest component to sea level rise over the next hundred years. Deep ocean temperatures change only slowly; therefore, thermal expansion would continue for many centuries even if the atmospheric concentrations of greenhouse gases were to stabilise.

The amount of warming and the depth of water affected vary with location. In addition, warmer water expands more than colder water for a given change in temperature. The geographical distribution of sea level change results from the geographical variation of thermal expansion, changes in salinity, winds, and ocean circulation. The range of regional variation is substantial compared with the global average sea level rise.

ii. Rise in sea Level: Sea level also changes when the mass of water in the ocean increases or decreases. This occurs when ocean water is exchanged with the water stored on land. The major land store is the water frozen in glaciers or ice sheets. Indeed, the main reason for the lower sea level during the last glacial period was the amount of water stored in the large extension of the ice sheets on the continents of the Northern Hemisphere. After thermal expansion, the melting of mountain glaciers and ice caps is expected to make the largest contribution to the rise of sea level over the next hundred years. These glaciers and ice caps make up only a few per cent of the world's land-ice area, but they are more sensitive to climate change than the larger ice sheets in Greenland and Antarctica, because the ice sheets are in colder climates with low precipitation and low melting rates. Consequently, the large ice sheets are expected to make only a small net contribution to sea level change in the coming decades.

\subsubsection{Widespread ocean acidification}

A new study says the seas are acidifying ten times faster today than 55 million years ago when a mass extinction of marine species occurred. And, the study concludes, current changes in ocean chemistry due to the burning of fossil fuels may portend a new wave of die-offs. In other words, the vast clouds of shelled creatures in the deep oceans had virtually disappeared. Many scientists now agree that this change was caused by a drastic drop of the ocean's $\mathrm{pH}$ level. The seawater became so corrosive that it ate away at the shells, along with other species with calcium carbonate in their bodies. It took hundreds of thousands of years for the oceans to recover from this crisis, and for the sea floor to turn from red back to white. The clay that the crew of the JOIDES Resolution dredged up may be an ominous warning of what the future has in store. By spewing carbon dioxide into the air, we are now once again making the oceans more acidic.

\subsection{Historical impacts of climate change}

Approximately one millennium after the $7 \mathrm{Ka}\left(32^{\text {nd }}\right.$ Century BCE) slowing of sea-level rise, many coastal urban centers rose to prominence around the world (Day, John W., et al. 2007). It 
has been hypothesized that this is correlated with the development of stable coastal environments and ecosystems and an increase in marine productivity (also related to an increase in temperatures), which would provide a food source for hierarchical urban societies.

The last written records of the Norse Greenlanders are from a 1408 marriage in the church of Hvalsey - today the best-preserved of the Norse ruins. Climate change has been associated with the historical collapse of civilizations, cities and dynasties. Notable examples of this include the Anasazi (Demenocal, P. B. 2001), Classic Maya (Hodell, David A., 1995), the Harappa, the Hittites, and Ancient Egypt (Jonathan Cowie, 2007). Other, smaller communities such as the Viking settlement of Greenland (transl. with introd. by Magnus Magnusson, 1983), have also suffered collapse with climate change being a suggested contributory factor (Diamond, Jared, 2005).

There are two proposed methods of Classic Maya collapse: environmental and nonenvironmental. The environmental approach uses paleoclimatic evidence to show that movements in the intertropical convergence zone likely caused severe, extended droughts during a few time periods at the end of the archaeological record for the classic Maya (Haug, Gh, et al., 2003). The non-environmental approach suggests that the collapse could be due to increasing class tensions associated with the building of monumental architecture and the corresponding decline of agriculture (Hosler D, et al., 1977), increased disease (Santley, Robert S.,et al., 1986) and increased internal warfare (Foias, Antonia E., et al.,1997). The Harappa and Indus civilizations were affected by drought 4,500-3,500 years ago. A decline in rainfall in the Middle East and Northern India 3,800-2,500 is likely to have affected the Hittites and Ancient Egypt.

Notable periods of climate change in recorded history include the medieval warm period and the little ice age. In the case of the Norse, the medieval warm period was associated with the Norse age of exploration and arctic colonization, and the later colder periods led to the decline of those colonies (Patterson, W.P., et al., 2007). Climate change in the recent past may be detected by corresponding changes in settlement and agricultural patterns. Archaeological evidence, oral history and historical documents can offer insights into past changes in the climate. Climate change effects have been linked to the collapse of various civilizations.

\subsection{Global warming impacts of climate change}

According to different levels of future global warming, impacts of climate has been used in the IPCC's Assessment Reports on climate change (Schneider DH, et al., 2007). The instrumental temperature record shows global warming of around $0.6^{\circ} \mathrm{C}$ over the entire $20^{\text {th }}$ century (IPCC 2007d.1). The future level of global warming is uncertain, but a wide range of estimates (projections) have been made (Fisher, BS et al., 2007). The IPCC's "SRES" scenarios have been frequently used to make projections of future climate change (Karl, 2009). Climate models using the six SRES "marker" scenarios suggest future warming of 1.1 to $6.4{ }^{\circ} \mathrm{C}$ by the end of the 21st century (above average global temperatures over the 1980 to 1999 time period as shown in Fig.3) (IPCC 2007d.3). The projected rate of warming under these scenarios would very likely be without precedent during at least the last 10,000 years (IPCC 2001-SPM). The most recent 
warm period comparable to these projections was the mid-Pliocene, around 3 million years ago (Stern N., 2008). At that time, models suggest that mean global temperatures were about 2 $3^{\circ} \mathrm{C}$ warmer than pre-industrial temperatures (Jansen E., et al., 2007).

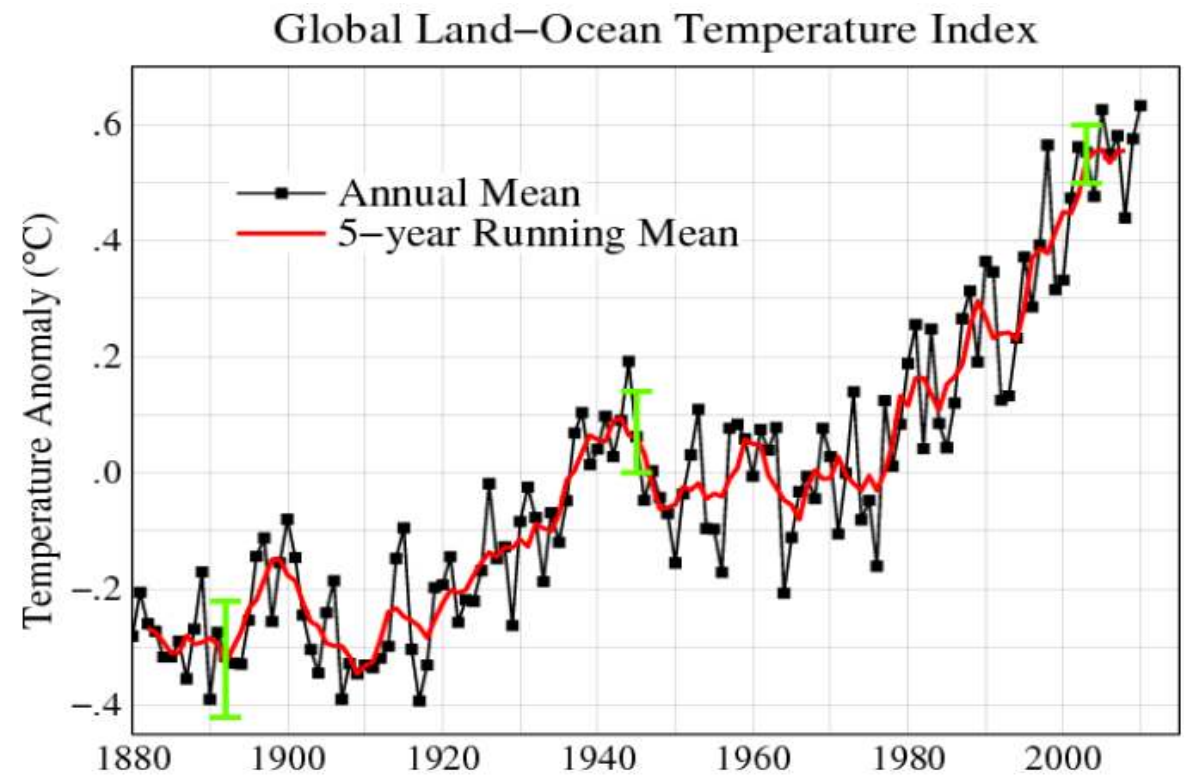

Figure 3. Global Land-Ocean, mean surface temperature difference from the average for 1880-2009 (Courtesy: Wikipedia.com)

The most recent report IPCC projected that during the 21st century the global surface temperature is likely to rise a further 1.1 to $2.9^{\circ} \mathrm{C}\left(2\right.$ to $\left.5.2{ }^{\circ} \mathrm{F}\right)$ for the lowest emissions scenario used in the report and 2.4 to $6.4^{\circ} \mathrm{C}\left(4.3\right.$ to $\left.11.5^{\circ} \mathrm{F}\right)$ for the highest (Fig.4).

\subsection{Physical impacts of climate change}

Working Group I's contribution to the IPCC Fourth Assessment Report, published in 2007, concluded that warming of the climate system was "unequivocal" (Solomon S, 2007a). This was based on the consistency of evidence across a range of observed changes, including increases in global average air and ocean temperatures, widespread melting of snow and ice, and rising global average sea level(Solomon S, 2007b).

Human activities have contributed to a number of the observed changes in climate (Hegerl GC, et. al., 2007). This contribution has principally been through the burning of fossil fuels, which has led to an increase in the concentration of GHGs in the atmosphere. This increase in GHG concentrations has caused a radiative forcing of the climate in the direction of warming. Human-induced forcing of the climate has likely to contributed to a number of observed changes, including sea level rise, changes in climate extremes (such as warm and cold days), declines in Arctic sea ice extent, and to glacier retreat (Fig.5 \& 6). 


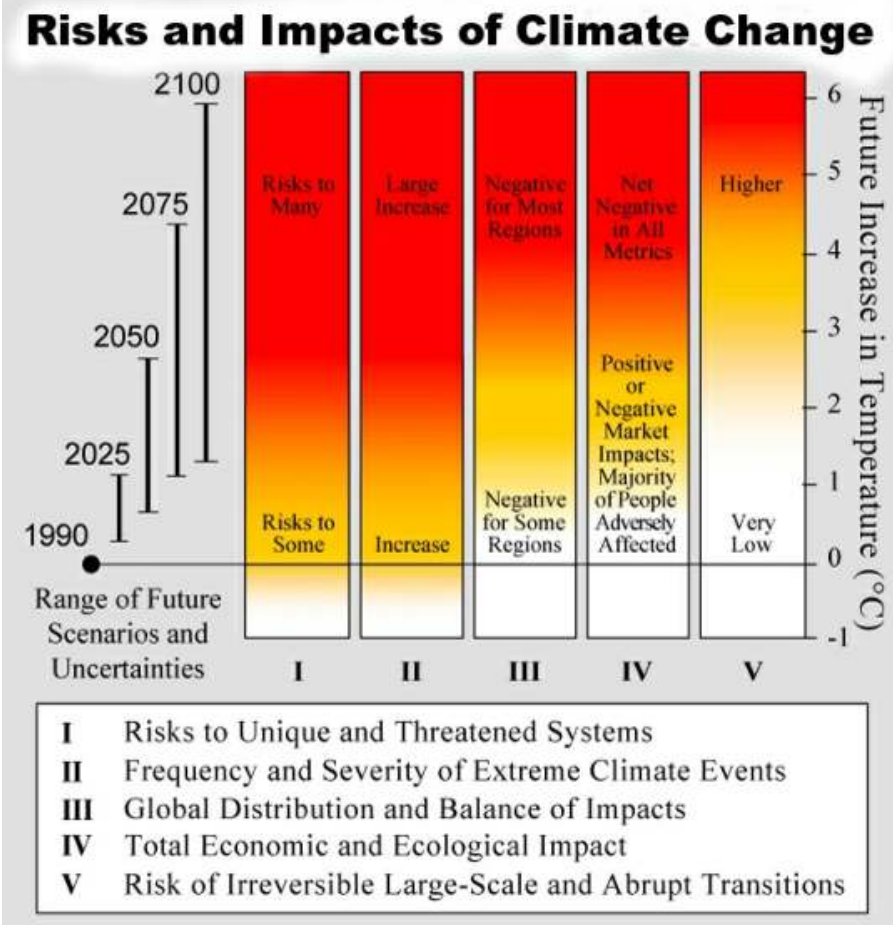

Figure 4. Projected Global Temperature Rise 1.1 to $6.4^{\circ} \mathrm{C}$ during 21st century (Courtesy: Wikipedia.com)

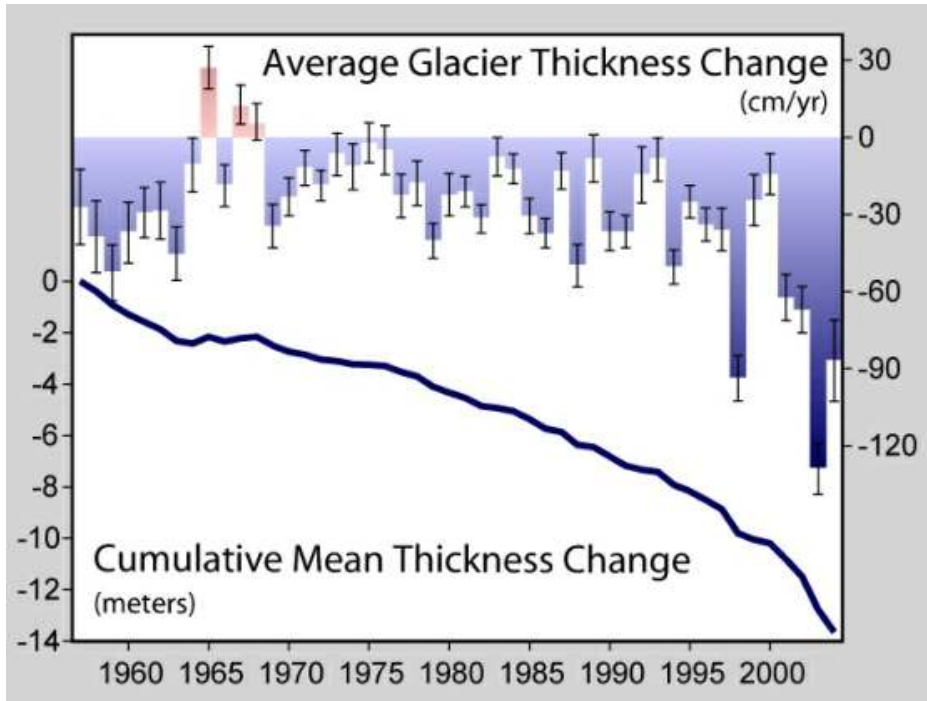

Figure 5. Decline in thickness of glaciers worldwide over the past half-century 


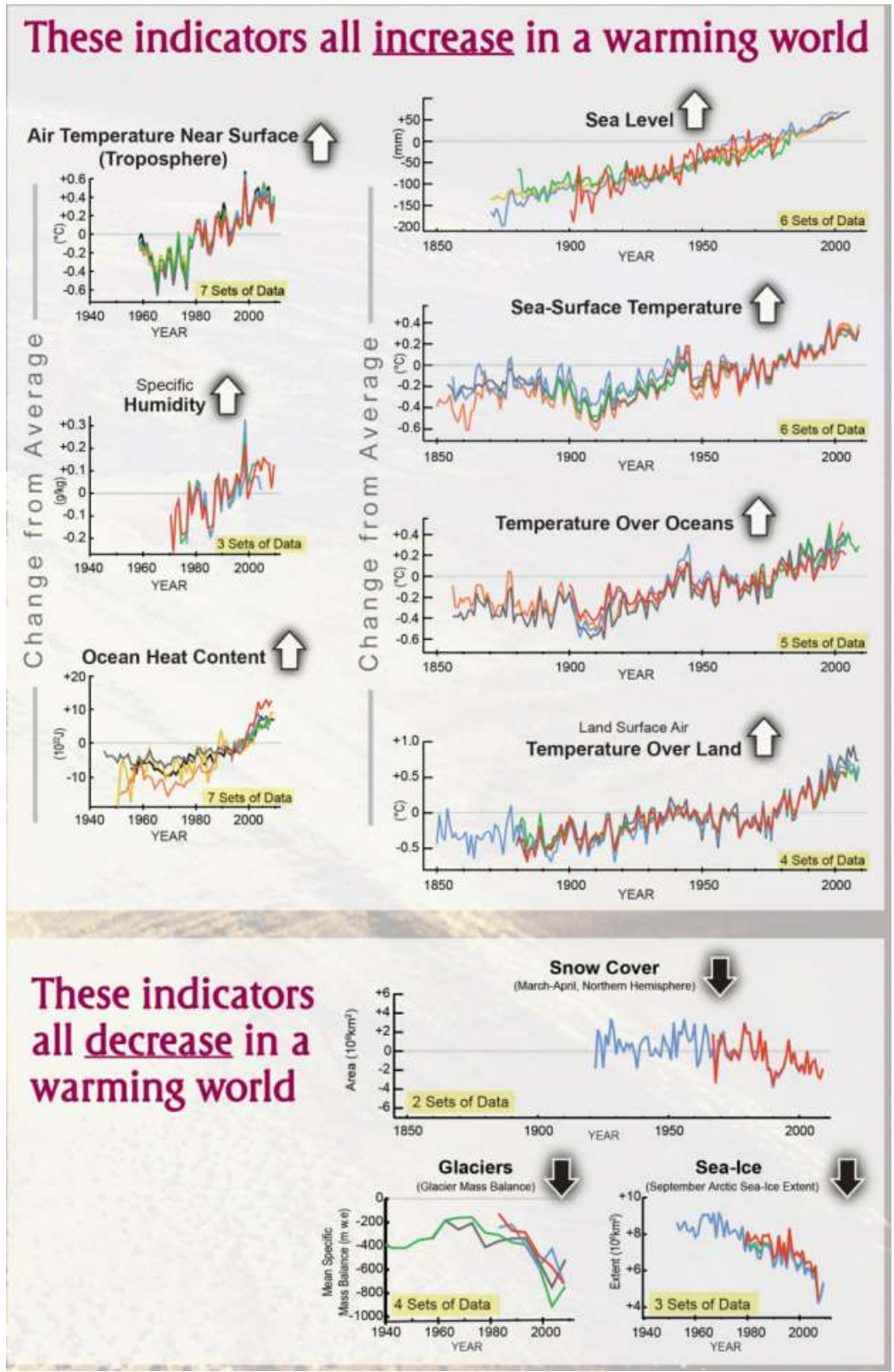

Figure 6. Key climate indicators that show global warming (Courtesy: Wikipedia.com)

Human-induced warming could potentially lead to some impacts that are abrupt or irreversible. The probability of warming having unforeseen consequences increases with the rate, magnitude, and duration of climate change. 


\subsection{Climate change effects on weather}

Observations show that there have been changes in weather (Le Treut H, et. al., 2007). As climate changes, the probabilities of certain types of weather events are affected. Changes have been observed in the amount, intensity, frequency, and type of precipitation. Widespread increases in heavy precipitation have occurred, even in places where total rain amounts have decreased. IPCC (2007d) concluded that human influences had, more likely than not (greater than $50 \%$ probability, based on expert judgment), contributed to an increase in the frequency of heavy precipitation events. Projections of future changes in precipitation show overall increases in the global average, but with substantial shifts in where and how precipitation falls. Climate models tend to project increasing precipitation at high latitudes and in the tropics (e.g., the south-east monsoon region and over the tropical Pacific) and decreasing precipitation in the sub-tropics (e.g., over much of North Africa and the northern Sahara).

Evidence suggests that, since the 1970s, there have been substantial increases in the intensity and duration of tropical storms and hurricanes. Models project a general tendency for more intense but fewer storms outside the tropics.

\subsection{Extreme weather, tropical cyclone, and list of atlantics hurricane records}

Since the late 20th century, changes have been observed in the trends of some extreme weather and climate events, e.g., heat waves. Human activities have, with varying degrees of confidence, contributed to some of these observed trends. Projections for the $21^{\text {st }}$ century suggest continuing changes in trends for some extreme events (Fig.7). Solomon et al. (2007), for example, projected the following likely (greater than $66 \%$ probability, based on expert judgment) changes:

- $\quad$ an increase in the areas affected by drought;

- increased tropical cyclone activity; and

- $\quad$ increased incidence of extreme high sea level (excluding tsunamis).

Projected changes in extreme events will have predominantly adverse impacts on ecosystems and human society.

\subsubsection{Triggering earthquakes, tsunamis, avalanches and volcanic eruptions}

Scientists are to outline dramatic evidence that global warming threatens the planet in a new and unexpected way - by triggering earthquakes, tsunamis, avalanches and volcanic eruptions. It is assessed that the Melting glaciers will set off avalanches, floods and mud flows in the Alps and other mountain ranges; torrential rainfall in the UK is likely to cause widespread erosion; while disappearing Greenland and Antarctic ice sheets threaten to let loose underwater landslides, triggering tsunamis that could even strike the seas around Britain.

At the same time the disappearance of ice caps will change the pressures acting on the Earth's crust and set off volcanic eruptions across the globe. Life on Earth faces a warm future - and a fiery one. 


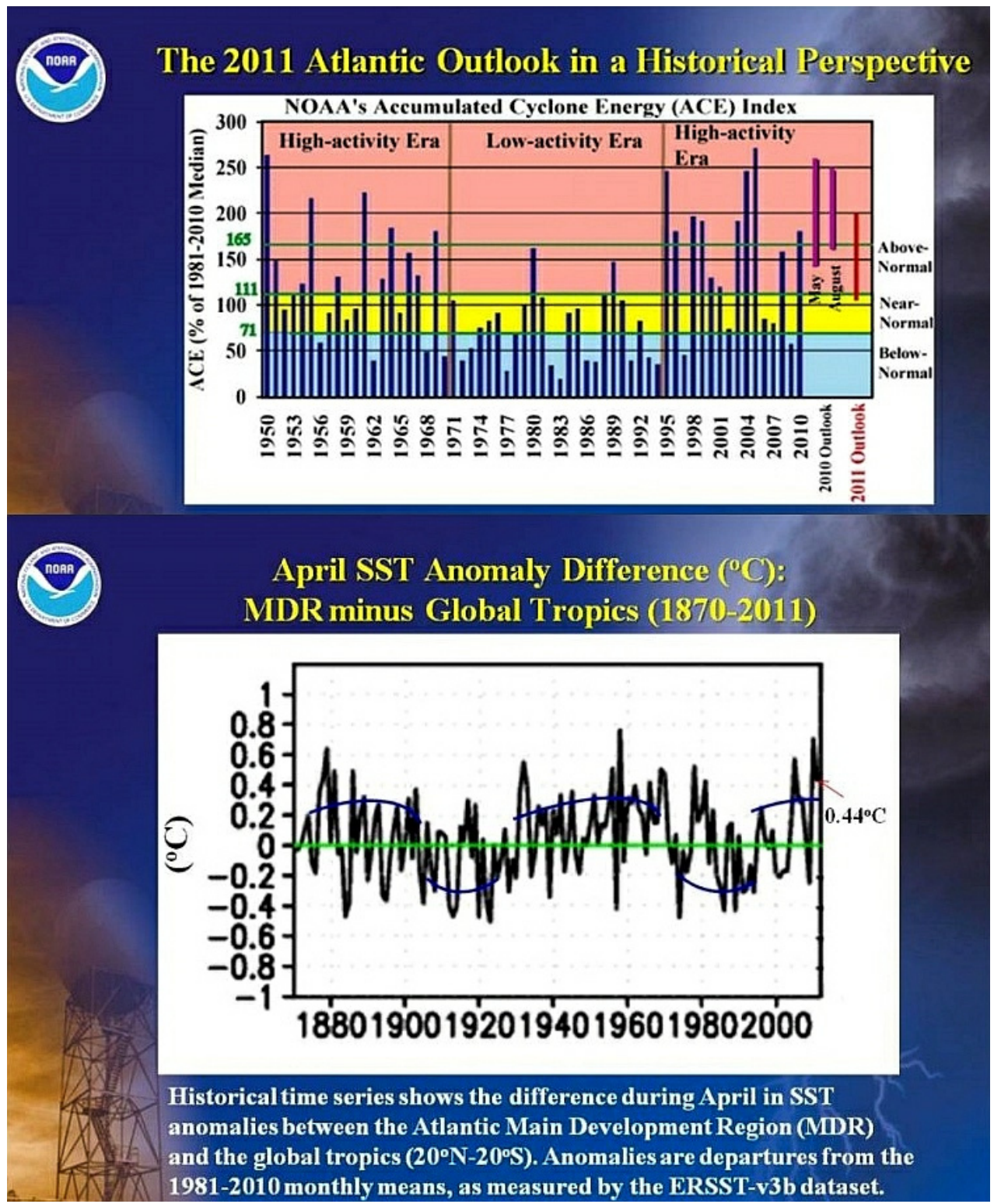

Figure 7. Accumulated cyclone energy in the Atlantic Ocean and the sea surface temperature difference which influences such, measured by the U.S. NOAA.

Not only are the oceans and atmosphere conspiring against us, bringing baking temperatures, more powerful storms and floods, but the crust beneath our feet seems likely to join in too, said Professor Bill McGuire, director of the Benfield Hazard Research Centre, at University College London (UCL). 
Maybe the Earth is trying to tell us something, added McGuire, who is one of the organisers of UCL's Climate Forcing of Geological Hazards. Some of the key evidence will come from studies of past volcanic activity. These indicate that when ice sheets disappear the number of eruptions increases, said Professor David Pyle, of Oxford University's earth sciences department.

The last ice age came to an end between 12,000 to 15,000 years ago and the ice sheets that once covered central Europe shrank dramatically, added Pyle. The impact on the continent's geology can be measured by the jump in volcanic activity that occurred at this time.

In the Eiffel region of western Germany a huge eruption created a vast caldera, or basinshaped crater, 12,900 years ago, for example. This has since flooded to form the Laacher See, near Koblenz. Scientists are now studying volcanic regions in Chile and Alaska - where glaciers and ice sheets are shrinking rapidly as the planet heats up - in an effort to anticipate the eruptions that might be set off.

Recently scientists from Northern Arizona University reported in the journal Science that temperatures in the Arctic were now higher than at any time in the past 2,000 years. Ice sheets are disappearing at a dramatic rate - and these could have other, unexpected impacts on the planet's geology.

According to Professor Mark Maslin of UCL, one is likely to be the release of the planet's methane hydrate deposits. These ice-like deposits are found on the seabed and in the permafrost regions of Siberia and the far north. These permafrost deposits are now melting and releasing their methane, said Maslin. You can see the methane bubbling out of lakes in Siberia. And that is a concern, for the impact of methane in the atmosphere is considerable. It is 25 times more powerful than carbon dioxide as a greenhouse gas.

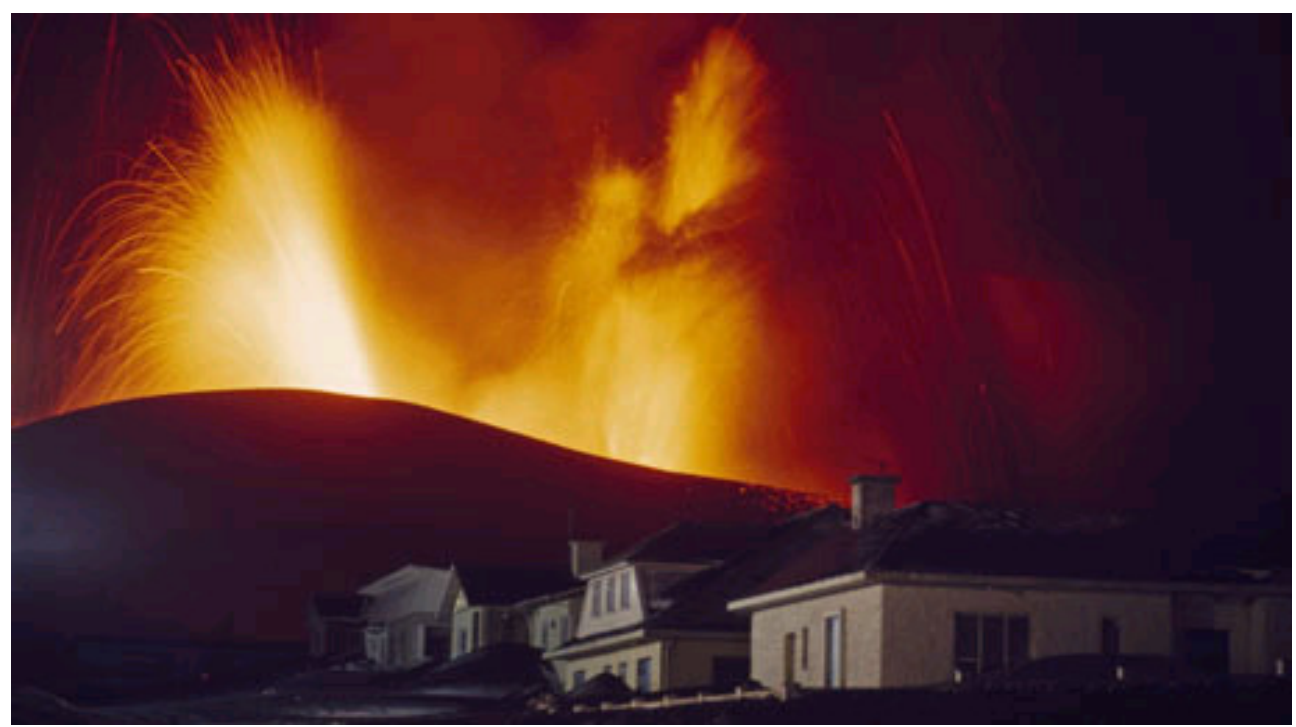

Figure 8. Earthquake 
A build-up of permafrost methane in the atmosphere would produce a further jump in global warming and accelerate the process of climate change. Even more worrying, however, is the impact of rising sea temperatures on the far greater reserves of methane hydrates that are found on the sea floor. It was not just the warming of the sea that was the problem, added Maslin. As the ice around Greenland and Antarctica melted, sediments would pour off land masses and cliffs would crumble, triggering underwater landslides that would break open more hydrate reserves on the sea-bed. Again there would be a jump in global warming. These are key issues that we will have to investigate over the next few years, he said.

There is also a danger of earthquakes, triggered by disintegrating glaciers, causing tsunamis off Chile, New Zealand and Newfoundland in Canada, NASA scientist Tony Song said recently (Fig.8). The last on this list could even send a tsunami across the Atlantic, one that might reach British shores. From other experts, it is said that the risk posed by melting ice in mountain regions, which would pose significant dangers to local people and tourists. The Alps, in particular, face a worryingly uncertain future, said Jasper Knight of Exeter University. Rock walls resting against glaciers will become unstable as the ice disappears and so set off avalanches. In addition, increasing melt-waters will trigger more floods and mud flows.

For the Alps this is a serious problem. Tourism is growing there, while the region's population is rising. Managing and protecting these people was now an issue that needed to be addressed as a matter of urgency, Knight said. "Global warming is not just a matter of warmer weather, more floods or stronger hurricanes. It is a wake-up call to Terra Firma," McGuire said.

\subsubsection{Major storms could submerge New York city in next decade}

Sea-level rise due to climate change could cripple the city in Irene-like storm scenarios, new climate report claims Irene-like storms of the future would put a third of New York City streets under water and flood many of the tunnels leading into Manhattan in under an hour because of climate change, a new state government report warns Wednesday $16^{\text {th }}$ Nov' $^{\prime} 2011$ (Fig.9).

Sea level rise due to climate change would leave lower Manhattan dangerously exposed to flood surges during major storms, the report, which looks at the impact of climate change across the entire state of New York, warns. The risks and the impacts are huge, said Art deGaetano, a climate scientist at Cornell University and lead author of the ClimAID study. Clearly areas of the city that are currently inhabited will be uninhabitable with the rising of the sea.

Factor in storm surges, and the scenario becomes even more frightening, he said. Subway tunnels get affected, airports - both LaGuardia and Kennedy sit right at sea level - and when you are talking about the lowest areas of the city you are talking about the business districts. The report, commissioned by the New York State Energy Research and Development 
Authority, said the effects of sea level rise and changing weather patterns would be felt as early as the next decade.

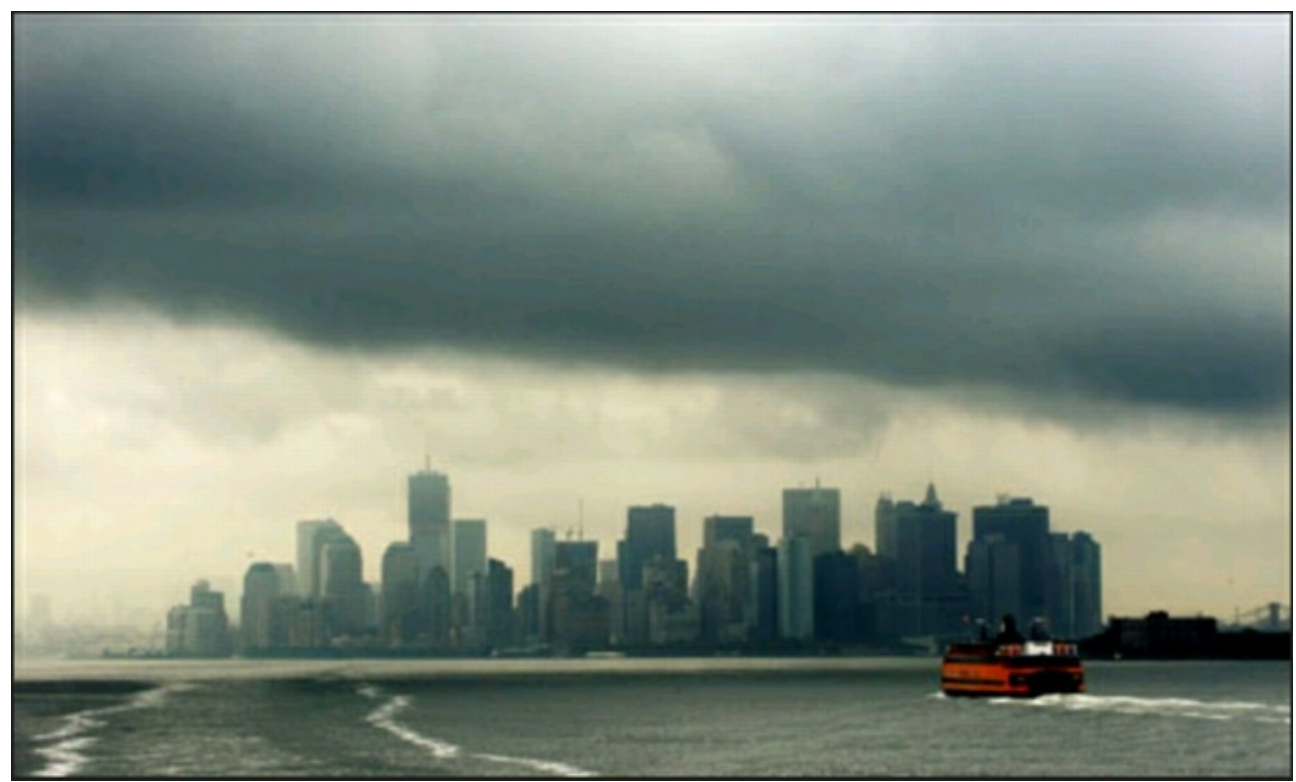

Figure 9. The Manhattan skyline as Hurricane Irene approached

By the mid-2020s, sea level rise around Manhattan and Long Island could be up to 10 inches, assuming the rapid melting of polar sea ice continues. By 2050, sea-rise could reach $2.5 \mathrm{ft}$ and more than $4.5 \mathrm{ft}$ by 2080 under the same conditions. In such a scenario, many of the tunnels subway, highway, and rail - crossing into the Bronx beneath the Harlem River, and under the East River would be flooded within the hour, the report said. Some transport systems could be out of operation for up to a month.

The report, which was two years in the making, was intended to help the New York state government take steps now to get people out of harm's way - and factor climate change into long-term planning to protect transport, water and sewage systems. New York mayor Michael Bloomberg was so concerned that he went on to commission an even more detailed study of the city after receiving early briefings on the report. That makes him an outlier among his fellow Republicans, who blocked funds for creating a new climate service in budget negotiations in Congress this week.

DeGaetano said climate change would force governments to begin rethinking infrastructure. Most of New York City's power plants, water treatment plants, and sewage systems are right at sea level. City planners are also going to have to help people adapt. More than half a million people live in the New York flood plain, and, as the report noted, a significant portion of them are African American and Latinos. And floods are not the only potential danger of climate change. The report notes that New York could face average annual 
temperature rises of up to 5 degrees Fahrenheit by the middle of this century and by as much as 9 degrees by 2080 .

In summer months, this could subject New Yorkers to power shortages and the risk of black-outs because of the extra need for air conditioning. Those without air conditioning - or who cannot afford the higher electricity bills - would be at greater risk of heat stroke. Those hotter conditions would have effects right across the state, playing havoc with New York State's wine and agricultural industries. Spruce and Fir trees would disappear from the Catskills and West Hudson River Valley, dairy cows would suffer heat stress, and popular apple varieties would decline, the report said.

\section{IPCC expected to confirm link between climate change and extreme weather}

Climate change is likely to cause more storms, floods, droughts, heatwaves and other extreme weather events, according to the most authoritative review yet of the effects of global warming. Report likely to conclude that man-made emissions are increasing the frequency of storms, floods and droughts on Thursday- 17 November 2011 16.32 GMT from New York. The Intergovernmental Panel on Climate Change will publish on 18 November 2011, its first special report on extreme weather, and its relationship to rising greenhouse gas emissions. The final details are being fought over by governments, as the "summary for policymakers" of the report has to be agreed in full by every nation that chooses to be involved. But the conclusions are expected to be that emissions from human activities are increasing the frequency of extreme weather events. In particular, there are likely to be many more heatwaves, droughts and changes in rainfall patterns.

Jake Schmidt of the US-based Natural Resources Defense Council said: This report should be a wake-up call to those that believe that climate change is some distant issue that might impact someone else. The report documents that extreme weather is happening now and that global warming will bring very dangerous events in the future. From the report you can see that extreme weather will impact everyone in one way or another. This is a window into the future if our political response doesn't change quickly.

This special report - one of only two that the IPCC is publishing before its 2014 comprehensive assessment of the state of climate change science - is particularly controversial as it deals with the relationship between man-made climate change and damaging events such as storms, floods and droughts. Some climate change skeptics and scientists cast doubt on whether the observed increase in extreme weather events can be attributed directly to human actions, or whether much of it is due to natural variability in the weather (Fig. 10).

The IPCC, a body of the world's leading climate scientists convened by the United Nations, is likely to conclude that extreme weather can be linked to man-made climate change, but that individual weather events can at present only rarely be linked directly to global warming. 
The Red Cross warned that disaster agencies were already dealing with the effects of climate change in vulnerable countries across the world. "The findings of this report certainly tally with what the Red Cross Movement is seeing, which is a rise in the number of weatherrelated emergencies around the world," said Maarten van Aalst, director of the Red Cross / Red Crescent Climate Centre and coordinating lead author of the IPCC report. "We are committed to responding to disasters whenever and wherever they happen, but we have to recognise that if the number of disasters continues to increase, the current model we have for responding to them is simply impossible to sustain."

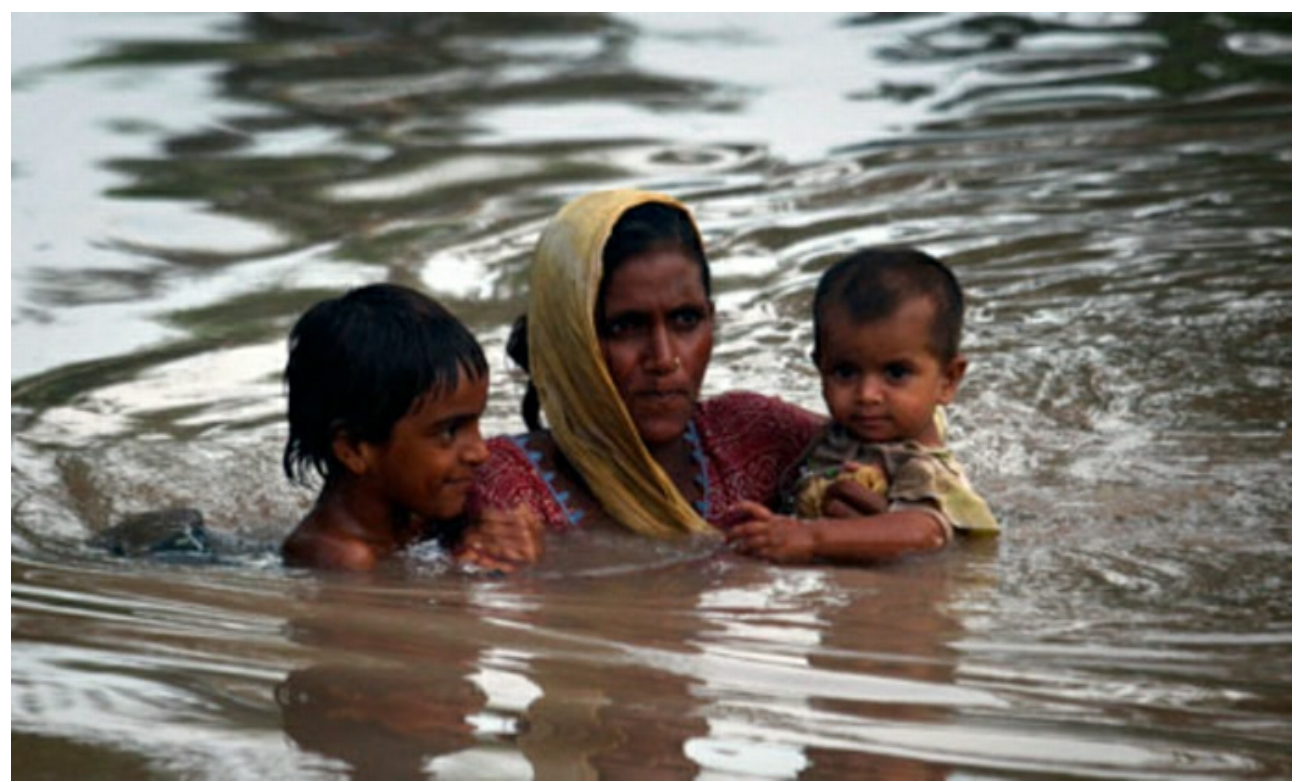

Figure 10. A Pakistani mother carries her children through flood waters in 2010. The IPCC report deals with the relationship between man-made climate change and extreme weather. (Photograph:

K.M.Chaudary/AP)

Insurers are also worried. Mark Way, of the insurance giant Swiss Re, told the Guardian that the massive increase in insurance claims was causing serious concern. He said that between 1970 and 1989, the insurance industry globally had paid out an average of $\$ 5$ bn a year in weather-related claims, but that this had increased enormously to $\$ 27 \mathrm{bn}$ a year. Although not all of this was attributable to climate change - increasing population, urbanisation and prosperity also play a major part - he said insurers wanted governments to get to grips with the effects of climate change in order to prepare for likely damage and tackle the causes of global warming.

Mike Hulme at the Tyndall Centre said it would be dangerous for governments to use this report in order to justify directing overseas aid only to those countries that could be proved to be suffering from climate change, rather than other problems. In that scenario, he said: "Funding will no longer go to those who are most at risk from climate-impacts and with low 
adaptive capacity, but will go to those who are lucky enough to live in regions of the world where weather extremes happen to be most attributable by climate models to human agency. These regions tend to be in mid-to-high latitudes, with lots of good weather data and well calibrated models. So, goodbye Africa."

\section{Conclusion}

From the various studies and reports, it is evident that the with the current rate of carbon dioxide release in the atmosphere there would not only be the increase in the global temperature, but it will also cause rise in sea, level and increase the frequency of disasters. The following major challenges are noticed from the above study:

- Emissions from human activities are increasing the frequency of extreme weather events. In particular, there are likely to be many more heatwaves, droughts and changes in rainfall patterns.

- $\quad$ The temperature is estimated to increase by 2 to $6^{\circ}$ Celsius within year 2100 , which is a tremendous increase from our current average temperature of $1.7^{\circ}$ Celsius (IPCC).

- By the mid-2020s, sea level rise around Manhattan and Long Island could be up to 10 inches, assuming the rapid melting of polar sea ice continues. By 2050, sea-rise could reach $2.5 \mathrm{ft}$ and more than $4.5 \mathrm{ft}$ by 2080 under the same conditions.

- Global warming threatens the planet in a new and unexpected way - by triggering earthquakes, tsunamis, avalanches and volcanic eruptions.

- Irene-like storms of the future would put a third of New York City streets under water and flood many of the tunnels leading into Manhattan in under an hour because of climate change.

These are few glimpses of future suspects; there may be much more bad implications of evils of climate change globally and humanity will be at high risk, developments will get shattered and rescue efforts will gain higher priorities

\section{Author details}

Bharat Raj Singh*

School of Management Sciences, Technical Campus, Lucknow, Uttar Pradesh, India

Onkar Singh

Harcourt Butler Technological Institute, Kanpur, Uttar Pradesh, India

\section{Acknowledgement}

Authors indebted to extend their thanks to the School of Management Sciences, Technical Campus, Lucknow and Harcourt Butler Technological Institute, Kanpur for providing the support of Library.

\footnotetext{
${ }^{*}$ Corresponding Author
} 


\section{References}

Crowley, T. J.; North, G. R. (May 1988), "Abrupt Climate Change and Extinction Events in Earth History", Science 240 (4855): 996-1002, Bib code: 1988Sci...240...996C, doi: 10.1126/science.240.4855.996, PMID 17731712.

Day, John W., et al. (2007). "Emergence of Complex Societies After Sea Level Stabilized". Eos Transactions American Geophysical Union 88 (15): 169. Bibcode 2007EOSTr..88..169D. doi:10.1029/2007EO150001.

Demenocal, P. B. (2001). "Cultural Responses to Climate Change During the Late Holocene". Science 292 (5517): 667-673. Bibcode 2001Sci...292..667D. doi:10.1126/science.1059827. PMID 11303088.

Desanker, P., et al., "Executive summary", In McCarthy 2001, Chapter 10: Africa, Retrieved 2011-06-20.

Diamond, Jared (2005), Collapse: How Societies Choose to Fail or Succeed. Viking Adult. ISBN 0670033375.

Easterling, WE, et al., "5.4.1 Primary effects and interactions", In Parry 2007, Chapter 5: Food, Fibre, and Forest Products, pp. 282, Retrieved 2011-06-25.

Fisher, BS, et al (2007). "3.1 Emissions scenarios", In B Metz, et al. Issues related to mitigation in the long term context. Climate Change 2007: Mitigation, Contribution of Working Group III to the Fourth Assessment Report of the Intergovernmental Panel on Climate Change, Cambrige, UK \& New York, NY, USA; CH: Cambridge University Press; IPCC, Retrieved: 2011-05-04.

Foias, Antonia E.; et al. (1997), "Changing Ceramic Production and Exchange in the Petexbatun Region, Guatemala: Reconsidering the Classic Maya Collapse". Ancient Mesoamerica 8 (2): 275. doi:10.1017/S0956536100001735.

Gille, Sarah T (February 15, 2002). "Warming of the Southern Ocean Since the 1950s", Science 295 (5558): 1275-7, Bibcode 2002Sci.295.1275G, doi:10.1126/science.1065863, PMID 11847337.

Goldemberg, 2006 J. Goldemberg, The promise of clean energy. Energy Policy, 34 (2006), pp. 2185-2190.

Haug, Gh., et al. (Mar 2003), "Climate and the collapse of Maya civilization". Science 299 (5613): 1731-5. Bibcode 2003Sci...299.1731H. doi:10.1126/science.1080444. ISSN 00368075. PMID 12637744.

Hodell, David A., et al. (1995), "Possible role of climate in the collapse of Classic Maya civilization". Nature 375 (6530): 391. Bibcode 1995Natur.375..391H. doi:10.1038/375391a0.

Hosler D., et al. (1977), "Simulation model development: a case study of the Classic Maya collapse". In Hammond, Norman; Thompson, John L.. Social process in Maya prehistory: studies in honour of Sir Eric Thompson. Boston: Academic Press. ISBN 0-12322050-5. 
Hubbert M.K., 1956, Nuclear energy and the fossil fuels; American Petroleum Institute, Drilling and Production Practice, Proc. Spring Meeting, San Antonio, Texas. 7-25

IEA, 2006 IEA, World Energy Outlook 2006, Organisation for Economic Co-operation and Development, International Energy Agency, Paris and Washington, DC (2006).

IEA, 2007a, IEA, Coal Information 2007, Organisation for Economic Co-operation and Development, International Energy Agency, Paris and Washington, DC (2007).

IEA, 2007b, IEA, World Energy Outlook 2007, China and India, Organisation for Economic Co-operation and Development, International Energy Agency, Paris and Washington, DC (2007).

Intergovernmental Panel on Climate Change (2007d), "Climate Change 2007: Synthesis Report, Contribution of Working Groups I, II and III to the Fourth Assessment Report of the Intergovernmental Panel on Climate Change (Core Writing Team et al. (eds.))". IPCC, Geneva, Switzerland, Retrieved: 2009-05-20.

IPCC (2001b), "Figure SPM-2", In McCarthy 2001, Summary for Policymakers, Retrieved: 2011-05-18.

IPCC 2001d, "3.16", Question 3, Retrieved: 2011-08-05.

IPCC 2007d, "1. Observed changes in climate and their effects", Summary for Policymakers, CH: IPCC, Retrieved: 2011-06-17.

IPCC 2007d, "3. Projected climate change and its impacts", Summary for Policymakers. CH: IPCC.

IPCC 2007d, "3.3.4 Ocean acidification", Synthesis Report, Retrieved: 2011-06-11.

IPCC 2007d, "5.2 Key vulnerabilities, impacts and risks-long-term perspectives", Synthesis report, Retrieved: 2011-08-05, IPCC, 2001, SPM Question 3.

Jansen, E, et al., "6.3.2 What Does the Record of the Mid-Pliocene Show?", In Solomon 2007, Chapter 6: Palaeoclimate. CH: IPCC Retrieved: 2011-05-04.

Jonathan Cowie, (2007), Climate change: biological and human aspects. Cambridge University Press. ISBN 0521696194, 9780521696197.

Karl, 2009, ed., "Global Climate Change".

Klass, 1998 D.L. Klass, Biomass for Renewable Energy, Fuels, and Chemicals, Academic Press, San Diego (1998).

Klass, 2003 D.L. Klass, A critical assessment of renewable energy usage in the USA. Energy Policy, 31 (2003), pp. 353-367.

Kundzewicz, Z.W., et al., "Executive Summary", In Parry 2007, Chapter 3: Fresh Water Resources and their Management, pp. 175, Retrieved: 2011-08-14.

Le Treut, H, et al. "FAQ 1.2 What is the Relationship between Climate Change and Weather?", In Solomon 2007, Historical Overview of Climate Change. CH: IPCC.

Lior, 2008, N. Lior, Energy resources and use the present situation and possible paths to the future, Energy, 33 (2008), pp. 842-857.

Parry 2007b, ed., "Magnitudes of impact", Summary for Policymakers, CH: Intergovernmental Panel on Climate Change, pp. 17, Retrieved: 2011-05-08. 
Parry 2007a, ed. "Definition of "biota". Appendix I: Glossary Retrieved: 2011-10-01.

Patterson, W.P., Dietrich, K.A., and Holmden, C., (2007), Sea Ice and sagas: stable isotope evidence for two millennia of North Atlantic seasonality on the north Icelandic shelf Arctic Natural Climate Change Workshop, Tromsø, Norway

Santley, Robert S., et al. (Summer 1986), "On the Maya Collapse". Journal of Anthropological Research 42 (2): 123-59.

Schneider, SH, et al., "19.3.2.1 Agriculture", In Parry 2007, Chapter 19: Assessing Key Vulnerabilities and the Risk from Climate Change, pp. 790, Retrieved: 2011-06-25.

Schneider, SH, et al., "19.3.1 Introduction to Table 19.1", In Parry 2007, Chapter 19: Assessing Key Vulnerabilities and the Risk from Climate Change. CH: IPCC, Retrieved: 2011-0504.

Scott, M., et al., "7.2.2.3.1 Migration", In McCarthy 2001, Chapter 7: Human Settlements, Energy, and Industry, Retrieved: 2011-08-29.

Scott, M.J., et al., "12.3.1 Population Migration", In Watson 1996, Chapter 12: Human Settlements in a Changing Climate: Impacts and Adaptation.

Shaffer, G.; Olsen, S. M.; Pedersen, J. O. P. (2009), “Long-term ocean oxygen depletion in response to carbon dioxide emissions from fossil fuels", Nature Geoscience 2 (2): 105109, Bibcode 2009NatGe.2.105S, doi:10.1038/ngeo420.

Shahriar Shafiee, Erkan Topal, When will fossil fuel reserves be diminished? Energy Policy, Volume 37, Issue 1, January 2009, Pages 181-189.

Singh, B.R., et al., A Study on Sustainable Energy Sources and its Conversion Systems Towards Development of an Efficient Zero Pollution Novel Air Turbine to Use as Prime-Mover to the Light Vehicle, ASME Conf. Proc., 2008, Volume 8, Paper no. IMECE2008-66803 pp. 371-378, doi: 10.1115/IMECE2008-66803.

Solomon 2007a, ed. "Direct Observations of Recent Climate Change", Summary for Policymakers, $\mathrm{CH}$ : Intergovernmental Panel on Climate Change.

Solomon, S, et al. 2007b "TS.3.4 Consistency Among Observations", In Solomon 2007, Technical Summary. CH: IPCC.

Solomon, S, et al. "Table TS.4", In Solomon 2007, Technical Summary, p. 52.

Stern, N (May 2008). "The Economics of Climate Change" (PDF). American Economic Review: Papers \& Proceedings (UK: LSE) 98 (2): 6, doi:10.1257/aer.98.2.1, Retrieved: 2011-05-04.

Transl. with introd. by Magnus Magnusson, (1983). The Vinland sagas: the Norse discovery of America. Harmondsworth, Middlesex: Penguin Books. ISBN 9780140441543.

WHO (2009), "2.6 Environmental risks", 2 Results, Global health risks: mortality and burden of disease attributable to selected major risks. Produced by the Department of Health Statistics and Informatics in the Information, Evidence and Research Cluster of the World Health Organization (WHO). World Health Organization, 20 Avenue Appia, 1211 Geneva 27, Switzerland, WHO Press, ISBN: 978924156387 1, Retrieved: 2011-0714. 
Wilbanks, T., et al., "7.4.1 General effects: Box 7.2, Environmental migration", In Parry 2007, Chapter 7: Industry, Settlement and Society, Retrieved 2011-08-29. 